\title{
Dynamic Contrast-Enhanced Magnetic Resonance Enterography and Dynamic Contrast-Enhanced Ultrasonography in Crohn's Disease: An Observational Comparison Study
}

\section{(1)(1) (9)}

\section{Authors}

Rune Wilkens ${ }^{1},{ }^{3}$, David A. Peters ${ }^{2}$, Agnete H. Nielsen ${ }^{1}$, Valeriya P. Hovgaard ${ }^{1}$, Henning Glerup ${ }^{1}$, Klaus Krogh

\section{Affiliations}

1 Divisions of Medicine and Radiology, Diagnostic Centre, Silkeborg Regional Hospital, University Research Clinic for Innovative Diagnostic Pathways, Silkeborg, Denmark

2 Department of Clinical Engineering, Aarhus University Hospital, Aarhus N, Denmark

3 Department of Hepatology and Gastroenterology, Aarhus University Hospital, Aarhus C, Denmark

Key words

ultrasonography, magnetic resonance imaging, Crohn's disease, reproducibility of results, contrast media

received 31.05 .2016

revised $\quad 19.09 .2016$

accepted 04.12.2016

Bibliography

DOI http://dx.doi.org/10.1055/s-0042-123841

Published online: 2017 | Ultrasound Int Open 2017; 3: E13-E24

(c) Georg Thieme Verlag KG Stuttgart · New York

ISSN 2199-7152

Correspondence

Dr. Rune Wilkens

Diagnostic Centre, Divisions of Medicine and Radiology

Silkeborg Regional Hospital

University Research Clinic for Innovative Diagnostic Pathways
Falkevej 1-3

8600 , Silkeborg

Denmark

Tel.: +45/272/02 147

runetw@gmail.com

\section{ABSTRACT}

Purpose Cross-sectional imaging methods are important for objective evaluation of small intestinal inflammation in Crohn's disease (CD). The primary aim was to compare relative parameters of intestinal perfusion between contrast-enhanced ultrasonography (CEUS) and dynamic contrast-enhanced magnetic resonance enterography (DCE-MRE) in CD. Furthermore, we aimed at testing the repeatability of regions of interest (ROIs) for CEUS.

Methods This prospective study included 25 patients: 12 females (age: 37 , range: 19-66) with moderate to severe CD and a bowel wall thickness $>3 \mathrm{~mm}$ evaluated with DCE-MRE and CEUS. CEUS bolus injection was performed twice for repeatability and analyzed in VueBox ${ }^{\circledR}$. Correlations between modalities were described with Spearman's rho, limits of agreement (LoA) and intraclass correlation coefficient (ICC). ROI repeatability for CEUS was assessed.

Results The correlation between modalities was good and very good for bowel wall thickness (ICC $=0.71, P<0.001)$ and length of the inflamed segment $(I C C=0.89, P<0.001)$. Moderate-weak correlations were found for the time-intensity curve parameters: peak intensity $(r=0.59, P=0.006)$, maximum wash-in-rate $(r=0.62, P=0.004)$, and wash-in perfusion index $(r=0.47, P=0.036)$. Best CEUS repeatability for peak enhancement was a mean difference of $0.73 \mathrm{~dB}(95 \% \mathrm{Cl}: 0.17$ to $1.28, P=0.01$ ) and $95 \%$ LoA from -3.8 to $5.3 \mathrm{~dB}$. Good quality of curve fit improved LoA to -2.3 to $2.8 \mathrm{~dB}$.

Conclusion The relative perfusion of small intestinal $C D$ assessed with DCE-MRE and CEUS shows only a moderate correlation. Applying strict criteria for ROIs is important and allows for good CEUS repeatability.

\section{Abbreviations}

$\begin{array}{ll}\text { AIU } & \text { Arbitrary intensity units } \\ \text { CEUS } & \text { Contrast-enhanced ultrasound } \\ \text { CD } & \text { Crohn's disease } \\ \text { CDAI } & \text { Crohn's Disease Activity Index } \\ \text { CDI } & \text { Color Doppler imaging } \\ \text { DCE-MRE } & \begin{array}{l}\text { Dynamic contrast-enhanced mag } \\ \text { enterography }\end{array} \\ \text { HBI } & \text { Harvey Bradshaw Index } \\ \text { ICC } & \text { Intraclass correlation coefficient } \\ \text { LoA } & \text { Limits of agreement } \\ \text { QoF } & \text { Quality of fit } \\ \text { ROI } & \text { Region of interest }\end{array}$

TIC Time-intensity curve

US Ultrasonography

\section{Introduction}

In Crohn's disease (CD) the grading of disease activity has shifted from subjective clinical scoring systems towards more objective measurements, in combination with patient-reported outcomes [1]. Endoscopy, although not completely objective, is often considered a gold standard for luminal disease in the colon, rectum, and sometimes the terminal ileum. However, endoscopy is of limited use in stricturing and proximal disease [2] and even well-recognized endoscopic scoring systems are not fully reliable [3]. This calls for cross-sectional imaging methods with objective parame- 


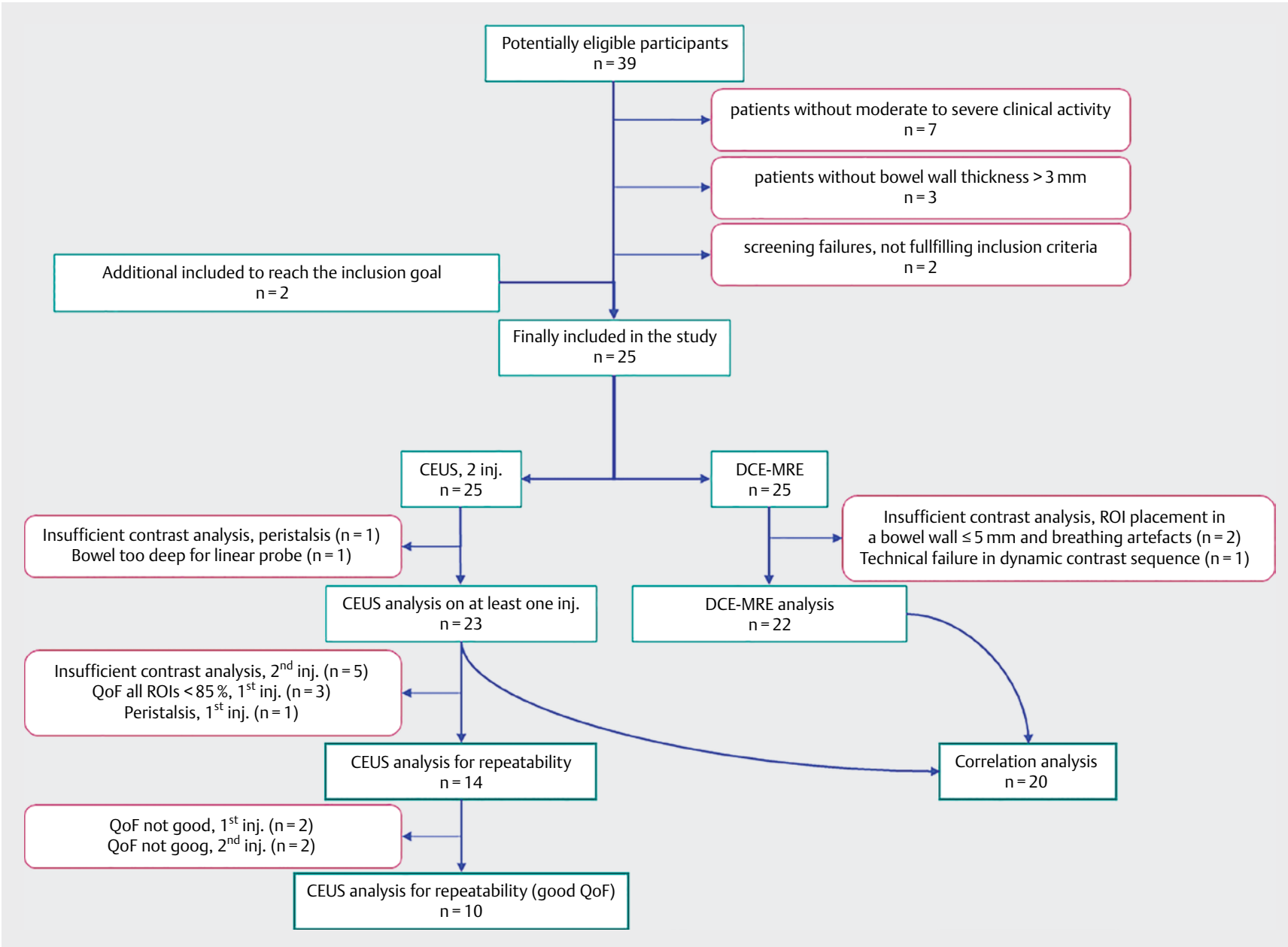

- Fig. 1 Flowchart of inclusion and analysis. Purple-colored boxes show the reason for no inclusion, exclusion or no analysis. The large number of patients with insufficient contrast analysis of $2^{\text {nd }}$ contrast injection is due to in-and-out-of-plane motion artifacts in the non-optimal scan plane. CEUS = contrastenhanced ultrasound, DCE-MRE $=$ dynamic contrast-enhanced magnetic resonance enterography, QoF $=$ quality of fit, inj. $=$ injection(s)

ters of disease severity $[1,4]$. Currently there is no single imaging modality as the gold standard for transmural disease of the small intestine [5].

The most consistent characteristic of disease activity on imaging is an increased bowel wall thickness of more than $3 \mathrm{~mm}[4,6,7]$. Nevertheless, the intestinal wall may be thickened not only by active disease but also by fibrosis [7,8]. Other features of inflammatory activity comprise ulcerations, T2-hypersignal, perimural signal, contrast enhancement, comb sign, enlarged lymph nodes, fistulas, abscesses and strictures described in the development of the MR intestinal activity score and MR enterography global assessment $[7,9,10]$. Unfortunately, experts do not agree about the importance of the individual findings [11].

In recent classifications, increased contrast enhancement is considered a relevant marker of disease activity $[7,9,12,13]$. This is in accordance with the characteristics of active inflammation including dilated leaking vessels [14] and neoangiogenesis [15]. Additionally, microvascular density has been shown to correlate with intensity on dynamic contrast-enhanced ultrasound (CEUS) [16]. Therefore, dynamic imaging techniques could potentially be used for evaluating disease activity and efficacy of treatment $[7,17]$.
The 2 promising modalities to assess relative bowel wall perfusion are CEUS and dynamic contrast-enhanced MR enterography (DCE-MRE). However, there are significant differences in contrast behavior between modalities. MR gadolinium-based contrast agents are relatively small and exhibit extravasation over time, whereas CEUS gas-filled lipid-shell contrast acts as a true intravascular agent. The time-intensity curves (TICS) recorded from the former are therefore a combination of perfusion and permeability, rather than perfusion alone. The relationship between signal intensity and MRI contrast agent concentration is complex and depends on a number of parameters, such as the native tissue relaxation rate, relaxivity of the contrast agent, local field inhomogeneity and the applied flip angle and inversion-recovery time [18]. US contrast agent on the other hand has a direct correlation with the signal intensity measured in $\mathrm{dB}$ [19]. Since perfusion is difficult to measure if the bowel wall is less than $3 \mathrm{~mm}$ thick [20], the parameters should only be used for grading disease activity or to follow treatment efficacy $[6,21]$.

In the present study, we hypothesized that intensity and time parameters of the initial time-intensity curves correlate well between modalities as the amount of MR contrast which is extravasated during the initial pass is low. 
- Table 1 Patient demographics.

\begin{tabular}{|c|c|}
\hline Parameter & No. of Patients \\
\hline Included patients & 25 \\
\hline Female & $13(52)$ \\
\hline Age, years & 37 [19-66] \\
\hline Body mass index $\left(\mathrm{kg} / \mathrm{m}^{2}\right)$ & $24.5 \pm 4.4$ \\
\hline \multicolumn{2}{|l|}{ Disease duration } \\
\hline$<2$ years & $10(40)$ \\
\hline $2-10$ years & $6(24)$ \\
\hline$>10$ years & $7(28)$ \\
\hline Unknown & $2(8)$ \\
\hline \multicolumn{2}{|l|}{ Location of disease } \\
\hline Terminal Ileum & $16(64)$ \\
\hline Colon & $1(4)$ \\
\hline Ileocolon & $6(24)$ \\
\hline Upper disease & $0(0)$ \\
\hline Unknown & $2(8)$ \\
\hline \multicolumn{2}{|l|}{ Medical therapy, n (\%) } \\
\hline None & $11(44)$ \\
\hline Corticosteroids & $5(20)$ \\
\hline Immunomodulators & $6(24)$ \\
\hline Biological therapy & $2(8)$ \\
\hline Combo treatment & $1(4)$ \\
\hline Crohn's Disease Activity Index & $298 \pm 85$ \\
\hline Harvey Bradshaw Index & $9.9 \pm 3.5$ \\
\hline Fecal calprotectin $(\mu \mathrm{g} / \mathrm{g})^{*}$ & $356[63-3600]$ \\
\hline C-reactive protein $(\mathrm{mg} / \mathrm{l})^{*}$ & $5.9[0.7-34.4]$ \\
\hline Hemoglobin (mmol/l) & $8.6 \pm 0.8$ \\
\hline Albumin $(\mathrm{g} / \mathrm{l})$ & $36.7 \pm 4.5$ \\
\hline Vitamin D (nmol/l) & $65 \pm 20.5$ \\
\hline Hematocrit & $0.40 \pm 0.035$ \\
\hline Time between examinations, days ${ }^{*}$ & $0[0-4]$ \\
\hline \multicolumn{2}{|l|}{ Symptoms within last flair, $n$ (\%), days * } \\
\hline Pain & $\begin{array}{l}23(92), 157 \text { days } \\
{[11-2906]}\end{array}$ \\
\hline Nausea & $\begin{array}{l}17 \text { (68), } 70 \text { days } \\
{[3-2495]}\end{array}$ \\
\hline Vomit & 11 (44), 35 days [3-265] \\
\hline Diarrhea & $\begin{array}{l}19 \text { (76), } 303 \text { days } \\
{[3-5751]}\end{array}$ \\
\hline Bloody stools & $6(24), 29.5$ days [5-105] \\
\hline Bloating & $\begin{array}{l}17(68), 166 \text { days } \\
{[26-4093]}\end{array}$ \\
\hline Weight loss & $\begin{array}{l}16(64), 108 \text { days } \\
{[3-2468]}\end{array}$ \\
\hline Fatigue & $\begin{array}{l}5(20), 189 \text { days } \\
{[22-1764]}\end{array}$ \\
\hline
\end{tabular}

Note - Numbers in parenthesis are percentages. Numbers in brackets are ranges

Unless otherwise indicated, data are means \pm standard deviations

${ }^{*}$ Median values and ranges
The main objective of this study was to compare objective parameters of relative perfusion obtained with DCE-MRE and CEUS in patients with moderate to severe CD. Our secondary objectives were to test the repeatability of regions of interest (ROIs) for CEUS and to evaluate the inter-rater reliability of $C D$ characteristics assessed with MRE and US.

\section{Materials and Methods}

This GCP monitored prospective double-blind observational study was approved by the Danish national authorities (2011-00588619) and the local research ethics committee (1-10-72-340-12) for the off-label use of US contrast agents. All participants gave written informed consent before entering the study. Inclusion criteria were known $C D$ with moderate to severe clinical activity based on either the CD Activity Index [22] (CDAI) > 220 or Harvey Bradshaw Index [23] (HBI) $>7$. Furthermore, patients had to be $\geq 18$ years of age and have a US-detectable intestinal segment with bowel wall thickness $>3 \mathrm{~mm}$. Patients were excluded if they were pregnant, breastfeeding or had any contraindications for DCE-MRE or CEUS.

25 patients (mean age: 37 years; range: $19-66$ years; 12 females) were recruited for the study from September 2012 to March 2014. Due to screening failure, 2 patients were excluded and another 2 were subsequently recruited to reach the desired inclusion of 25 patients, > Fig. 1. The Montreal classification [24], CDAI, HBI, gastrointestinal symptoms, smoking status, and medical history were recorded and blood and stool samples were taken during the first visit. For full patient demographics, \ Table 1.

\section{Ultrasonography}

Participants were investigated after a 4-h fast. Ultrasonography (US) was performed by one physician (RW) with 2 years of experience with the procedure. The investigator was blinded to the MRE scan and biochemical results. However, the patients' symptoms were known. An Acuson S3000 ultrasound machine with a 4-9 MHz linear matrix transducer and a $1-6 \mathrm{MHz}$ curvilinear transducer was used (Siemens Medical Solutions, Malvern, PA). Color Doppler imaging (CDI) was set with a transmit frequency of $6.75 \mathrm{MHz}$, gain $1 \mathrm{~dB}$, pulsed repetition frequency 1099 , low wall filter of 2 , and a scale of $6 \mathrm{~cm} / \mathrm{s}$. The most severely inflamed bowel segment was identified based on wall thickness and the highest CDI signal score according to the Limberg classification [25]. The total length of each affected segment, bowel wall pattern, presence of ulcers, stenosis and prestenotic dilatation were registered.

All CEUS scans were performed on the Acuson machine using the $9\llcorner 4$ probe. The settings were: fixed mechanical index of $0.06-$ 0.08 , dynamic range 80 , frame rate of 10 per second, frequency $4 \mathrm{MHz}$, and the focal zone beneath the bowel wall. Sulfur hexafluoride microbubbles (SonoVue ${ }^{\circledR}$; Bracco Imaging, Milan, Italy) $2.4 \mathrm{ml} \times 2$ were injected by trained nurses followed by a $5 \mathrm{ml}$ saline flush over $2 \mathrm{~s}$. Scans were recorded for $90 \mathrm{~s}$. The scan plane was kept constant and patients were instructed regarding gentle breathing. More than $5 \mathrm{~min}$ after the first injection, the scan was repeated at the same spot, but in a different scan plane, to cover the segment in both the transverse and longitudinal axes. The chosen bowel segments were terminal ileum, neo-terminal ileum or proximal ileum. 

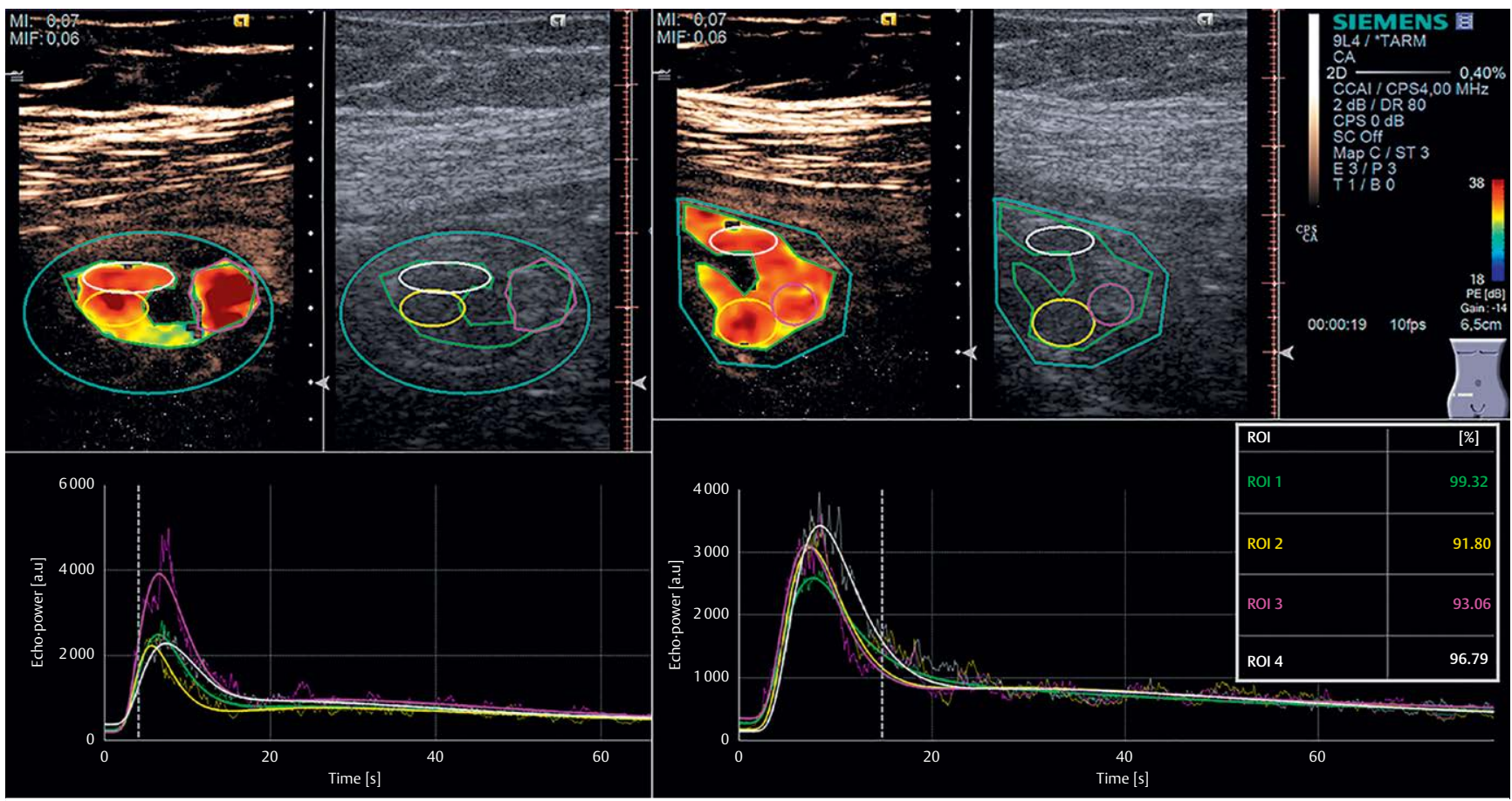

- Fig. 2 Contrast-enhanced ultrasonography with SonoVue in a 66-year-old woman. Quantification using VueBox. Upper left: Axial view of first bolus injection. The contrast image is seen on the left, while the corresponding B-mode image is shown on the right. The outer turquoise oval-shaped ROI is the area of investigation and motion compensation. The green region of interest (ROI) is ROI1 and the largest possible ROI. The yellow ROI is ROI2, the purple ROI is ROI3, and the fourth ROI is white. Lower left: Corresponding time intensity curves. Upper right: bowel in longitudinal scan after second bolus injection with 4 new ROIs. Lower right: TICs for injection 2. NB. Y-axis is slightly different from injection 1. Quality of fit is shown in the box on the right, indicating the largest ROI (ROI1) has the best curve fit. ROI2 and ROI3 are almost identical. $\mathrm{ROI}=$ region of interest.

The location for CEUS was determined as the most inflamed area of the segment according to a prior classification [12].

\section{Analysis of contrast-enhanced ultrasonography}

Cine loop files were exported in DICOM format, re-linearized, and quantified on VueBox ${ }^{\circledR} 5.1$ (Bracco Suisse SA, Geneva, Switzerland) as described earlier [17].

If possible, four ROIs were drawn using the following criteria: all ROIs had to be larger than $0.1 \mathrm{~cm}^{2}$ and within the bowel wall at all times. Shapes and placement of ROls were optimized to obtain a quality of fit (QoF) of the fitted curve larger than $90 \%$ or as high as possible. Built-in motion compensation was applied whenever beneficial. The first ROI was drawn as large as possible and typically covering the full bowel wall thickness of the anterior and posterior bowel wall avoiding the lumen. VueBox includes the possibility to apply a heat map for the parameters of interest. 3 additional ROIs were placed in areas with the highest peak enhancement according to the heat map and without overlapping, > Fig. 2 and video (Online Resource). Analyses were then compared for repeatability between the largest ROI, the maximum peak ROI and the mean of the 3 latter ROls, exhibiting a QOF $>85 \%$, entitled mean ROI. The average (log-converted) values of the best reproducible method were subsequently chosen for comparison with DCE-MRE results. Data post-processing was badge-analyzed by the same investigator more than 6 months after US and clinical scoring of the last patient to ensure effective blinding of data.

\section{Dynamic contrast-enhanced magnetic resonance enterography}

Patients were instructed to fast for $4 \mathrm{~h}$ and drink $1 \mathrm{I}$ of oral contrast $1 \mathrm{~h}$ before the scan. Oral contrast comprised a suspension of $125 \mathrm{ml}$ mannitol 15\% (Fresenius Kabi, Bad Homburg, Germany) in $875 \mathrm{ml}$ of tap water, $30 \mathrm{ml}$ psyllium HUSK ${ }^{\circledR}$ Fibre, and ice cubes. Peristalsis was suppressed by intravenous injection of $20 \mathrm{mg}$ hyoscine butylbromide (Buscopan ${ }^{\circledR}$; Boehringer Ingelheim, Ingelheim, Germany) prior to non-dynamic sequences and repeated before contrast injection. Images were acquired using a 1.5T MR unit (Avanto; Siemens, Erlangen, Germany) with patients in the prone position. The intravenous contrast agent used was gadoterate meglumine (Dotarem $^{\circledR}$; Guerbet, Villepinte, France) with $0.2 \mathrm{mg} / \mathrm{kg}$ bodyweight at $5 \mathrm{ml} / \mathrm{s}$ followed by a $24 \mathrm{ml}$ saline flush. Patients were instructed to hyperventilate prior to a long breath hold followed by gentle breathing. The MR scanning protocols can be seen in > Table 2 .

\section{Analysis of magnetic resonance enterography}

Interpretation of MRE-based pathoanatomical data was performed individually by 2 radiologists with 9 (AHN) and 4 (VPH) years of experience, respectively. Both were blinded to the findings on US. The maximum wall thickness and total length of disease were described in continuous measurements for the most pathological bowel segment. Average values between readers were used for comparison with bowel wall thickness and length of involvement measured on US. The presence of mural edema, ulcers, wall enhancement pattern, perimural involvement, and presence of complications like 


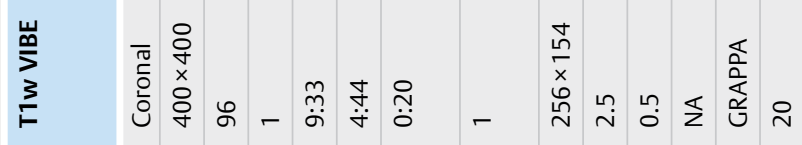

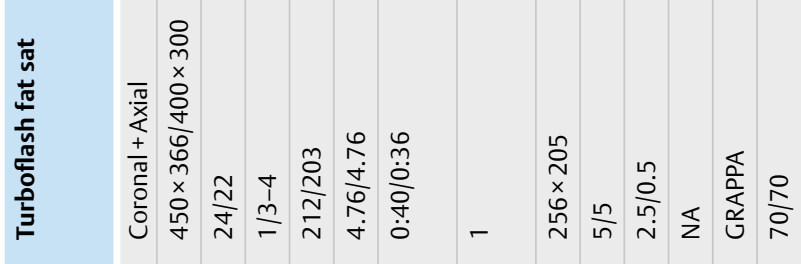

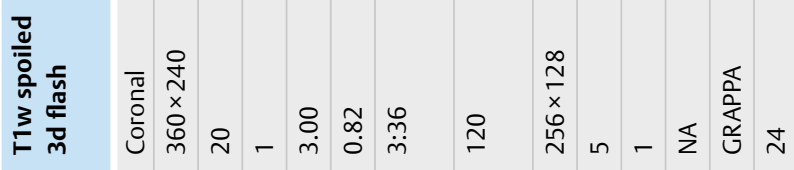

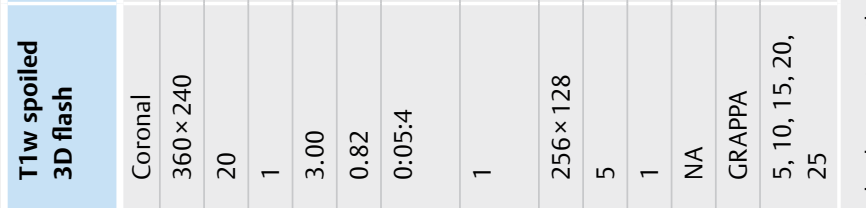

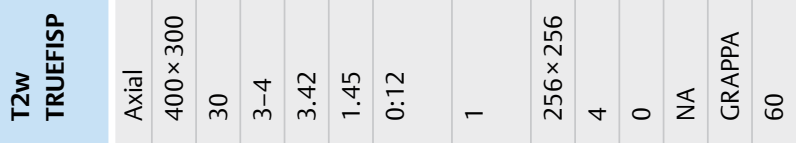

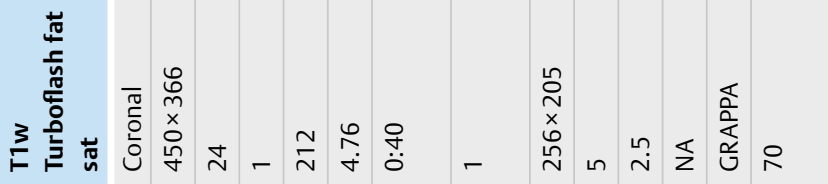

蒿京

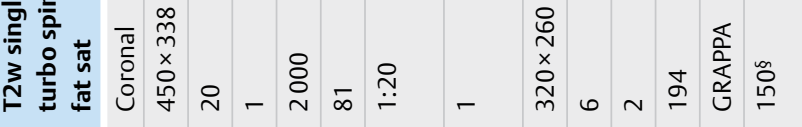

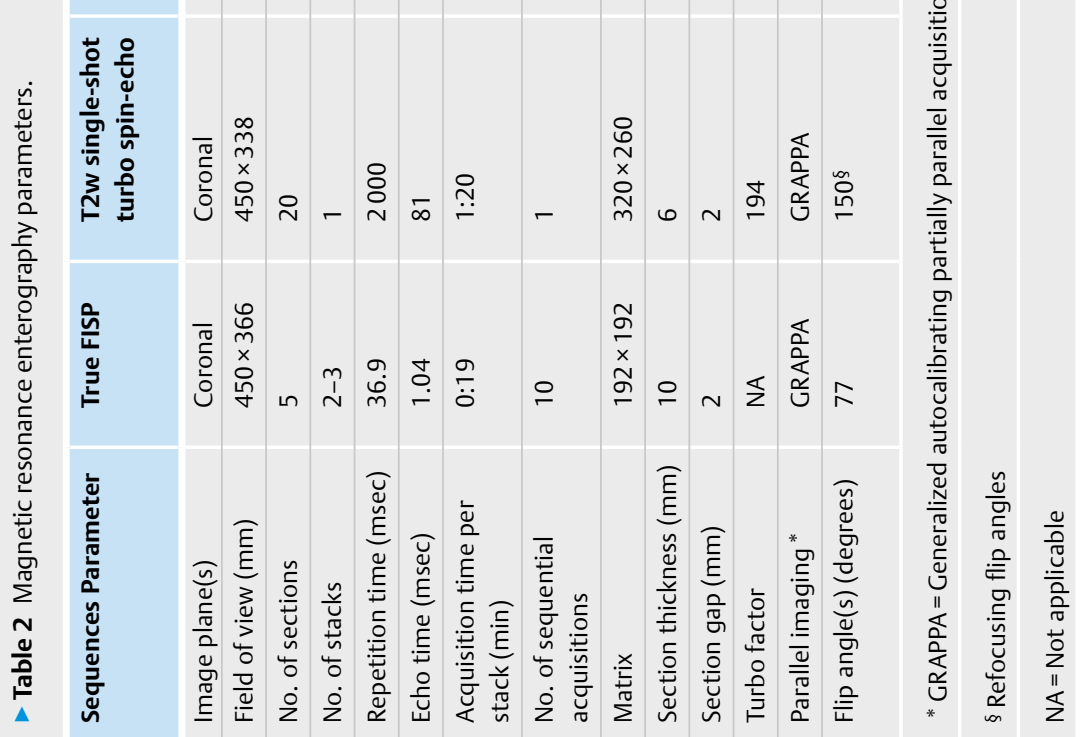




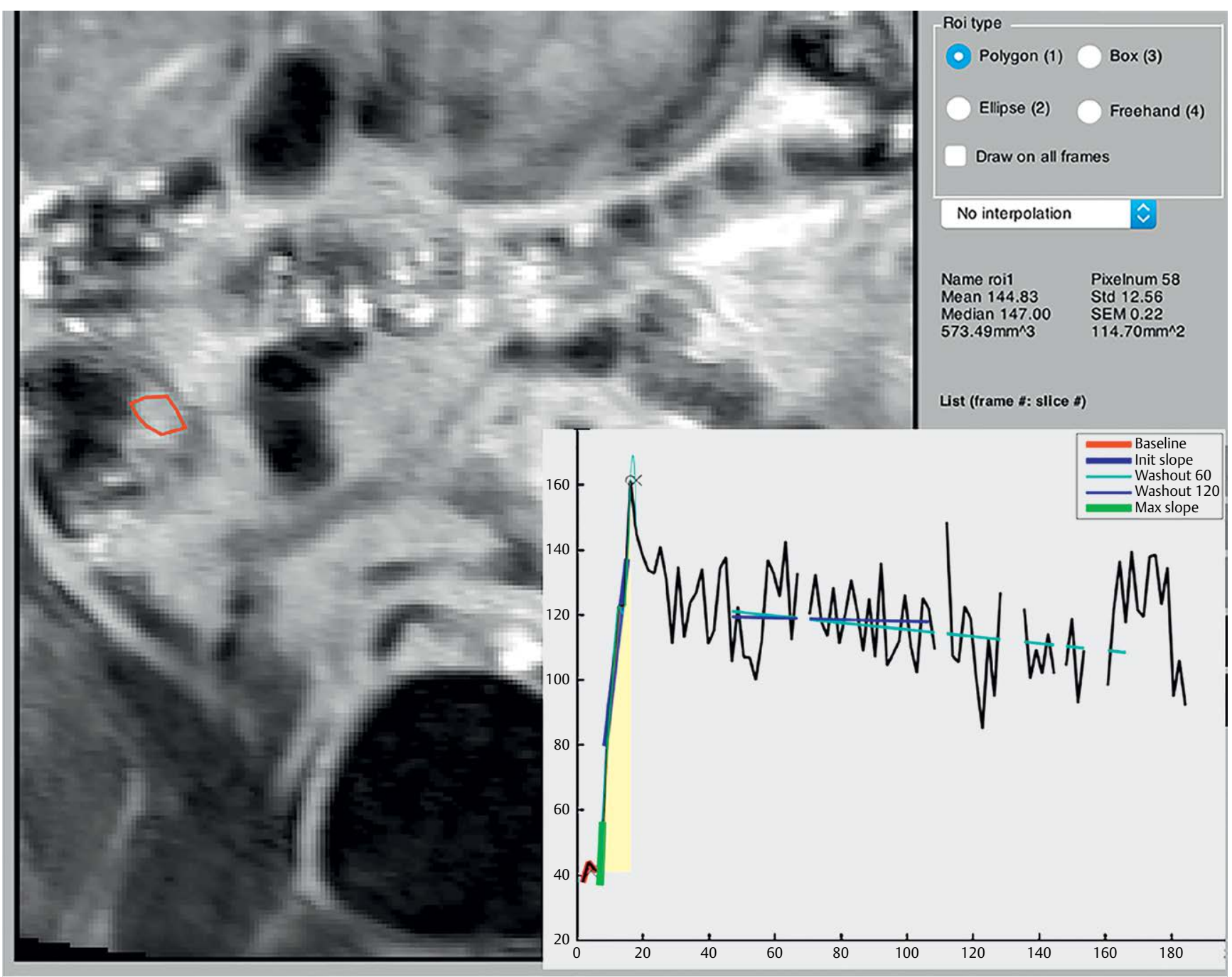

- Fig. 3 RoiTool. Dynamic contrast-enhanced MR enterography quantification, using RoiTool. Coronal T1- weighted spoiled 3D flash sequence of a 35-year-old woman. A region of interest is drawn within the thickened bowel at the terminal ileum. Corresponding graphs are produced in MatLab. The red line indicates the baseline. The bold blue line indicates the initial slope. The bold green line indicates the maximum slope. The yellow area shows the wash-in area under the curve. The two thin lines can calculate the plateau over time (not utilized in our study). ROI= region of interest.

stenosis and penetrating disease were also registered for the segment, based on the MRE global score $[9,10]$.

The ROI for DCE-MRE analysis was placed in the bowel wall at the site of the largest wall thickness and highest enhancement within the same bowel segment examined by CEUS, using a custom-made program in MATLAB ${ }^{\circledR}$ (MathWorks ${ }^{\circledR}$, Natick, MA). The ROI was manually moved in order to stay within the bowel wall during the dynamic series, - Fig. 3. TICs were interpolated using a cubic spline. This interpolated curve was used to derive the parameters described in > Table 3.

\section{Statistical analysis}

Statistical analysis was performed using Stata 13.1 for MAC (Stata Corp LP, College Station, TX). If no disease was observed on MRE, the bowel wall thickness was set to $3 \mathrm{~mm}$ and the length to $0 \mathrm{~cm}$. Existing data in the literature were too scarce to allow for a power calculation. However, we estimated 25 patients to be sufficient.
None of the linearized CEUS intensity data, expressed as arbitrary intensity units (AIU), followed a Gaussian distribution. Hence, they were log-converted as by default in US systems using $10 \times \log 10$ (AIU) and expressed in $\mathrm{dB}$ for further analysis [12]. Time parameters for both CEUS and DCE-MRE, C-reactive protein, and fecal-calprotectin were analyzed log-converted. Correlations between DCEMRE and CEUS TIC parameters were described with Spearman's correlation, since DCE-MRE data were slightly skewed [26] even with log-conversion. Correlation coefficients were interpreted as suggested earlier [26]. CEUS repeatability was assessed with $95 \%$ limits of agreement (LoA), using a mixed effect model with independent residuals per ROI [27]. Data for length of disease and MRE global score did not follow a Gaussian distribution regardless of log conversion. Hence only intraclass correlation coefficients (ICC) are reported for these data. P-values $<0.05$ were considered statistically significant. Data were not corrected for multiple testing. However, final conclusions were drawn having multiple testing in mind. 
- Table 3 Time intensity curve parameters, dynamic contrastenhanced magnetic resonance enterography.

\begin{tabular}{|c|c|}
\hline Value & Description \\
\hline Baseline & $\begin{array}{l}\text { Mean of initial frames before rapid rise in } \\
\text { enhancement. First frame was discarded. }\end{array}$ \\
\hline Peak & $\begin{array}{l}\text { Highest enhancement within first } 7 \text { frames } \\
(15 \mathrm{~s}) \text {. In the upslope, all preceding values } \\
\text { should present in an increasing manner. } \\
\text { Only a single dip was allowed. }\end{array}$ \\
\hline Rise time & Time between end of baseline and peak \\
\hline Peak enhancement & Absolute value between peak and baseline \\
\hline Slope & Peak enhancement divided by rise time \\
\hline Robust slope & $\begin{array}{l}\text { Best line fitted between values from } 25 \text { to } \\
75 \% \text { of peak enhancement }\end{array}$ \\
\hline Max slope & Steepest slope over an average of $1 \mathrm{~s}$ \\
\hline Wash-in AUC & $\begin{array}{l}\text { Area under curve from baseline to peak - } \\
\text { subtracted by baseline }\end{array}$ \\
\hline AUC70 s & Area under the curve within the first $70 \mathrm{~s}$ \\
\hline Time to peak & $\begin{array}{l}\text { Calculated time to peak enhancement } \\
\text { value based on extrapolation of the robust } \\
\text { slope }\end{array}$ \\
\hline $\mathrm{AUC}=$ area unc & \\
\hline
\end{tabular}

\section{Results}

All but 2 patients had CEUS and DCE-MRE performed within the same day. The remaining 2 patients were scanned 4 days apart. All patients completed both examinations without adverse events or serious discomfort.

\section{Pathoanatomical data}

The thickest bowel wall segments had a mean of $7.9 \mathrm{~mm}$ (range: 4-12 mm) when assessed with US and $8.1 \mathrm{~mm}$ (range: $4-14.5 \mathrm{~mm}$ ) when assessed with MRE. The mean difference was $0.22 \mathrm{~mm}$ (LoA - 4.3 to 3.9) and the corresponding ICC was 0.71 (0.44-0.86, $\mathrm{P}<0.001)$ ( $\vee$ Fig. 4). The median length of the inflamed segment was $15 \mathrm{~cm}$ (range $3-57 \mathrm{~cm}$ ) on US and $12 \mathrm{~cm}$ (range $1-70 \mathrm{~cm}$ ) on MRE. The corresponding ICC was $0.89(0.76-0.95, \mathrm{P}<0.001)$.

\section{Associations between perfusion data from con- trast-enhanced ultrasonography and dynamic con- trast-enhanced magnetic resonance enterography}

Data from 3 MRE and 2 CEUS scans were excluded from further analysis, $>$ Fig. 1. All compared segments were either from the terminal ileum $(n=19)$ or the ileum $(n=1)$.

The total area under curve, including wash-in and wash-out for CEUS and wash-in and plateau-phase at $70 \mathrm{~s}$ for DCE-MRE, had a

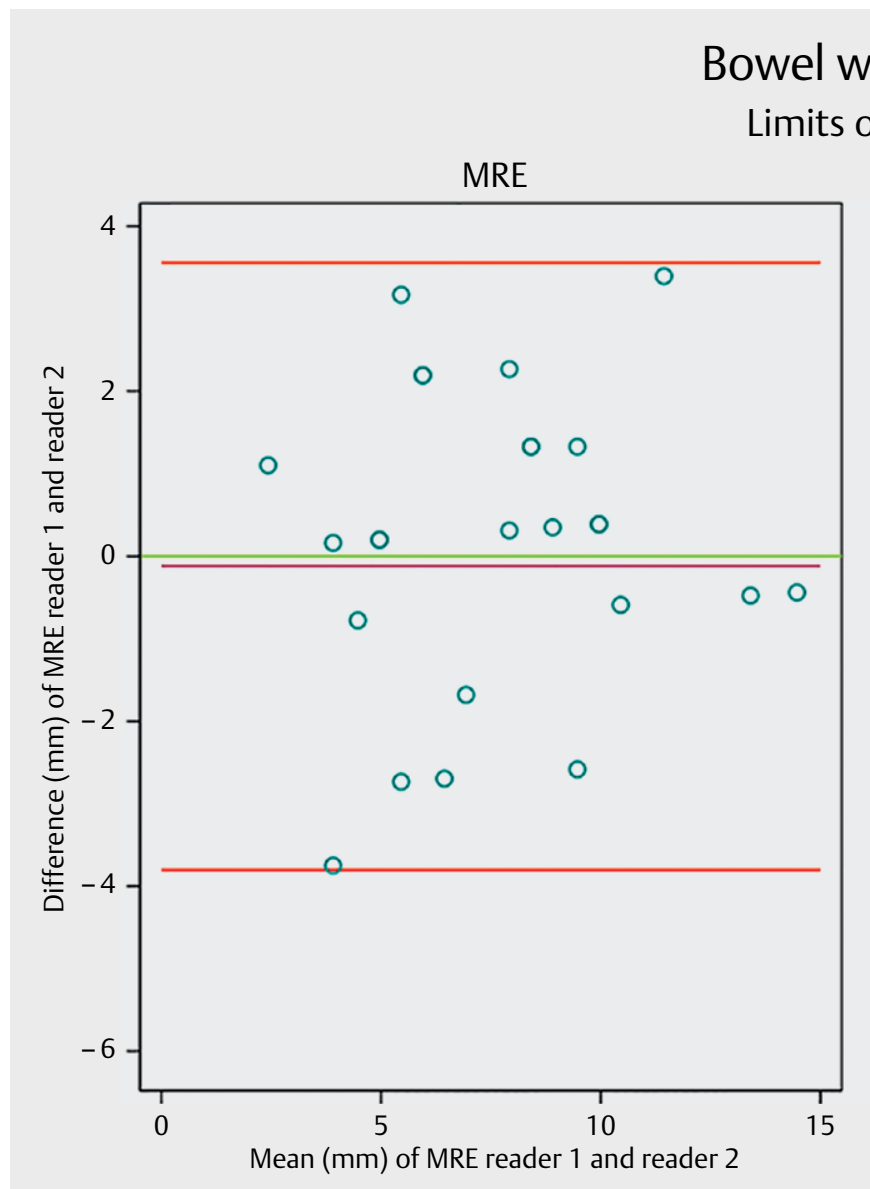

MRE vs. US

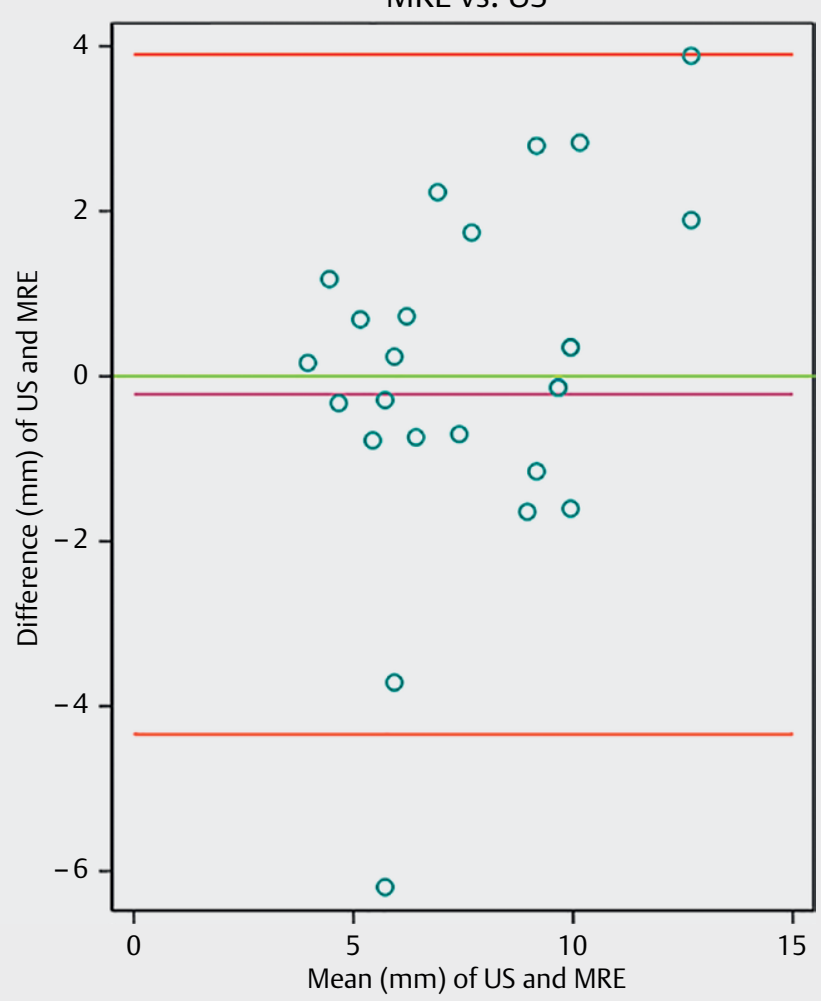

- Fig. 4 Limits of agreement for bowel wall thickness measured by ultrasound (US) and magnetic resonance enterography (MRE). The purple line shows the observed average agreement. The red lines indicate $95 \%$ limits of agreements and the green line is the perfect average agreement. MRE = magnetic resonance enterography, US = ultrasonography 


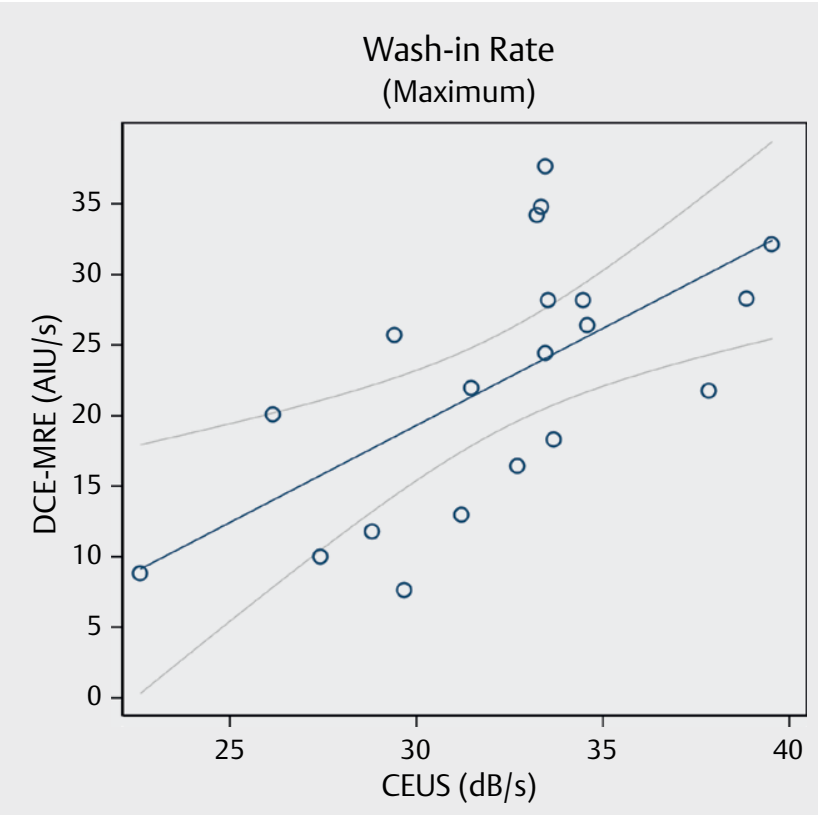

- Fig. 5 Scatter plot showing correlation between dynamic contrast-enhanced magnetic resonance enterography and contrast-enhanced ultrasound for maximum wash-in rate. Spearman's rho $=0.618, P=0.004$. MRE = magnetic resonance enterography. CEUS $=$ contrast-enhanced ultrasound. $\mathrm{AIU}=$ arbitrary intensity units .

low and insignificant correlation between the 2 methods $(r=0.16$, $P=0.494)$. The wash-in area under curve also showed poor correlation $(r=0.18, P=0.443)$. Likewise, the rise time and time to peak showed no correlation between modalities $(r=0.11, P=0.659$ and $r=0.02, P=0.930$, respectively). The slope and maximum slope for DCE-MRE and wash-in rate for CEUS correlated moderately well $(r=0.60, P=0.005$, and $r=0.62, P=0.004)$, $>$ Fig. 5 . The peak intensity and wash-in perfusion index determined by each of the 2 methods were moderately and moderately to weakly correlated $(r=0.59, P=0.006$ and $r=0.47, P=0.036$ respectively). No significant correlation was found between peak enhancement of CEUS and of DCE-MRE ( $r=0.41, P=0.076)$.

\section{Repeatability of contrast-enhanced ultrasonography and reproducibility of magnetic resonance enterog- raphy}

For CEUS, the smallest mean difference between 2 contrast injections was found for the maximum peak ROI. However, the narrowest limit of agreement was consistently found for the mean ROls,

- Table 4. In a post hoc analysis restricted to ROIs with QoF $>90 \%$, or if 2 ROls could not qualify for this, at least one ROI with QoF $>85 \%$ and the other $>90 \%$, LoA could be further reduced, > Fig. 6 and - Table 4 for all LoA, > Table 5 for QoF.

MRE interrater variability for bowel wall thickness showed an ICC $=0.83(0.66-0.92 \mathrm{P}<0.001)$ and ICC $=0.76(0.51-0.89$ $P<0.001)$ for length of involvement. The mean difference was $1.2 \mathrm{~mm}$ with $95 \%$ LoA from -3.8 to $3.6 \mathrm{~mm}$ for wall thickness. For reproducibility on MR enterography global score, $>$ Table 6.

\section{Discussion}

The present study compares CEUS and MRE for the description of the severity of ongoing small intestinal inflammation in CD. Even though correlations between basic pathoanatomical findings were good between the 2 modalities, our main finding was only a moderate to weak correlation when assessing relative changes in perfusion.

Since clinical activity scores for CD are poorly associated with the presence of active inflammation and equally poorly predict long-term outcome, their use should be supplemented by objective markers [1]. Therefore, cross-sectional imaging is of paramount importance as an adjunct to endoscopy [4]. Active inflammation is potentially treatable with effective medication but needs objective description and repeated follow-up to determine treatment response. Stenoses caused by fibrosis do not respond to medical treatment and need surgery [28]. In contrast to fibrosis [29], active inflammation causes hyperemia and hyperperfusion [30] which may be quantified by CEUS and MRE.

A few previous studies have shown a significant correlation between dynamic contrast-enhanced cross-sectional imaging and clinical disease activity, biochemistry [31], or a combined score for response [32], the need for surgery [20], and change in medication $[17,21,33]$. Other authors aimed at more objective endpoints like micro-vessel density [16] or mucosal healing or inactive disease defined by endoscopy [21]. However, the studies do not agree about which TIC parameters are important. Romanini et al. [16], Saevik et al. [17] and Horje et al. [34] found a statistically significant difference for almost all TIC parameters and disease activity, whereas others only showed significance for time to peak [31], area under curve [32], or peak enhancement [33]. In this present study, we found a significant correlation between the 2 modalities when describing peak and slope-related parameters but, surprisingly, not for area under curve, peak enhancement or rise time.

There is no consensus on how to perform or quantify intestinal perfusion measurement. Consequently, the heterogeneity between studies makes them difficult to compare or reproduce. For example, only a few authors have described the placement and analysis of ROIs for CEUS in detail [21] and only one group did log transformation of data before statistical analysis [35].

Several MRE studies use change in contrast enhancement as an indicator for disease activity $[13,29,30]$. However, most studies have not applied a dynamic protocol and only use a few image acquisitions or the relative change over a predefined timespan after injection. Taylor et al. found an inverse correlation with slope of enhancement on MRE and micro-vessel density [36], which is the opposite of the finding by Romanini et al. using CEUS [16]. These studies and our findings, showing a lack of good correlation, suggest that the 2 modalities measure somewhat dissimilar components of "perfusion", with DCE-MRE TIC measurements being a mixture of perfusion and extravasation. Taylor et al. also found a direct correlation with slope of enhancement and disease duration and speculated that increased enhancement could be caused by ischemia and arteriolar stenosis [36].

In the present study, the interrater variability for structural MRE findings was comparable to those reported in previous studies [37]. We only found a moderate correlation in wash-in rate and peak intensity could be established between DCE-MRE and CEUS. Lack of 
- Table 4 Repeatability of time intensity curve parameters, dynamic contrast-enhanced ultrasonography (CEUS).

\begin{tabular}{|c|c|c|c|c|c|}
\hline $\begin{array}{l}\text { CEUS parameter region } \\
\text { of interest (ROI) }\end{array}$ & $\begin{array}{l}\text { Mean difference between inj. } \\
1 \text { and inj. } 2\end{array}$ & P-value & $\begin{array}{l}\text { Limits of } \\
\text { agreement }\end{array}$ & $\begin{array}{l}\text { Difference from large } \\
\text { ROI }\end{array}$ & P-value \\
\hline \multicolumn{6}{|l|}{ Peak Enhancement } \\
\hline Large ROI & $1.36 \mathrm{~dB}(0.77-1.96)$ & $P<0.001$ & {$[-4.0$ to 6.8$] \mathrm{dB}$} & Reference & NA \\
\hline Good QoF & $-0.14 \mathrm{~dB}(-0.66$ to 0.38$)$ & $P=0.588$ & {$[-4.2$ to 3.9$] \mathrm{dB}$} & Reference & NA \\
\hline Maximum Peak ROI & $0.63 \mathrm{~dB}(0.05-1.20)$ & $P=0.032$ & {$[-4.4$ to 5.7$] \mathrm{dB}$} & $1.34 \mathrm{~dB}(0.93-1.75)$ & $P<0.0001$ \\
\hline Good QoF & $-0.49 \mathrm{~dB}(-0.89$ to -0.08$)$ & $P=0.018$ & {$[-3.7$ to 2.7$] \mathrm{dB}$} & $1.78 \mathrm{~dB}(1.45-2.10)$ & $P<0.0001$ \\
\hline Mean ROI & $0.73 \mathrm{~dB}(0.17-1.28)$ & $P=0.010$ & {$[-3.8$ to 5.3$] \mathrm{dB}$} & $0.90 \mathrm{~dB}(0.50-1.30)$ & $P<0.0001$ \\
\hline Good QoF & $0.24 \mathrm{~dB}(-0.13$ to 0.61$)$ & $P=0.198$ & {$[-2.3$ to 2.8$] \mathrm{dB}$} & $1.18 \mathrm{~dB}(0.87-1.50)$ & $P<0.0001$ \\
\hline \multicolumn{6}{|l|}{ Area under curve } \\
\hline Large ROI & $1.46 \mathrm{~dB}(0.78-2.13)$ & $P<0.0001$ & {$[-4.6$ to 7.5$] \mathrm{dB}$} & Reference & NA \\
\hline Good QoF & $0.46 \mathrm{~dB}(-0.03$ to 0.95$)$ & $P=0.068$ & {$[-3.4$ to 4.3$] \mathrm{dB}$} & Reference & NA \\
\hline Maximum Peak ROI & $0.18 \mathrm{~dB}(-0.34$ to 0.71$)$ & $P=0.489$ & {$[-4.3$ to 4.7$] \mathrm{dB}$} & $0.88 \mathrm{~dB}(0.46-1.30)$ & $P<0.0001$ \\
\hline Good QoF & $0.16 \mathrm{~dB}(-0.32$ to 0.63$)$ & $P=0.515$ & {$[-3.5$ to 3.8$] \mathrm{dB}$} & $1.31 \mathrm{~dB}(0.98-1.64)$ & $\mathrm{P}<0.0001$ \\
\hline Mean ROI & $0.64 \mathrm{~dB}(0.15-1.13)$ & $P=0.010$ & {$[-3.3$ to 4.6$] \mathrm{dB}$} & $0.32 \mathrm{~dB}(-0.09$ to 0.73$)$ & $P=0.122$ \\
\hline Good QoF & $0.75 \mathrm{~dB}(0.32-1.17)$ & $P<0.001$ & {$[-2.2$ to 3.7$] \mathrm{dB}$} & $0.79 \mathrm{~dB}(0.48-1.11)$ & $P<0.0001$ \\
\hline \multicolumn{6}{|l|}{ Wash - in rate } \\
\hline Large ROI & $1.41 \mathrm{~dB} / \mathrm{s}(0.74-2.09)$ & $\mathrm{P}<0.0001$ & {$[-4.7$ to 7.6$] \mathrm{dB} / \mathrm{s}$} & Reference & NA \\
\hline Good QoF & $-0.59 \mathrm{~dB} / \mathrm{s}(-1.09$ to -0.08$)$ & $P=0.023$ & {$[-4.6$ to 3.4$] \mathrm{dB} / \mathrm{s}$} & Reference & NA \\
\hline Maximum Peak ROI & $0.90 \mathrm{~dB} / \mathrm{s}(0.20-1.59)$ & $P=0.011$ & {$[-5.2$ to 7.0$] \mathrm{dB} / \mathrm{s}$} & $1.54 \mathrm{~dB} / \mathrm{s}(1.06-2.02)$ & $\mathrm{P}<0.0001$ \\
\hline Good QoF & $-0.68 \mathrm{~dB} / \mathrm{s}(-1.13$ to -0.24$)$ & $P=0.003$ & {$[-4.2$ to 2.8$] \mathrm{dB} / \mathrm{s}$} & $1.94 \mathrm{~dB} / \mathrm{s}(1.61-2.27)$ & $\mathrm{P}<0.0001$ \\
\hline Mean ROI & $0.61 \mathrm{~dB} / \mathrm{s}(-0.00$ to 1.23$)$ & $P=0.051$ & {$[-4.4$ to 5.6$] \mathrm{dB} / \mathrm{s}$} & $1.17 \mathrm{~dB} / \mathrm{s}(0.72-1.62)$ & $P<0.0001$ \\
\hline Good QoF & $-0.16 \mathrm{~dB} / \mathrm{s}(-0.53$ to 0.21$)$ & $P=0.393$ & {$[-2.8$ to 2.4$] \mathrm{dB} / \mathrm{s}$} & $1.35 \mathrm{~dB} / \mathrm{S}(1.04-1.66)$ & $\mathrm{P}<0.0001$ \\
\hline \multicolumn{6}{|l|}{ Wash-in perfusion index } \\
\hline Large ROI & $1.34 \mathrm{~dB} / \mathrm{s}(0.75-1.93)$ & $P<0.0001$ & {$[-4.0$ to 6.7$] \mathrm{dB} / \mathrm{s}$} & Reference & NA \\
\hline Good QoF & $-0.13 \mathrm{~dB} / \mathrm{s}(-0.64$ to 0.38$)$ & $P=0.616$ & {$[-4.2$ to 3.9$] \mathrm{dB} / \mathrm{s}$} & Reference & NA \\
\hline Maximum Peak ROI & $0.57 \mathrm{~dB} / \mathrm{s}(0.01-1.14)$ & $P=0.045$ & {$[-4.4$ to 5.5$] \mathrm{dB} / \mathrm{s}$} & $1.31 \mathrm{~dB} / \mathrm{s}(0.91-1.72)$ & $\mathrm{P}<0.0001$ \\
\hline Good QoF & $-0.50 \mathrm{~dB} / \mathrm{s}(-0.90$ to -0.10$)$ & $P=0.016$ & {$[-3.7$ to 2.7$] \mathrm{dB} / \mathrm{s}$} & $1.74 \mathrm{~dB} / \mathrm{s}(1.42-2.06)$ & $\mathrm{P}<0.0001$ \\
\hline Mean ROI & $0.71 \mathrm{~dB} / \mathrm{s}(0.17-1.26)$ & $P=0.011$ & {$[-3.8$ to 5.2$] \mathrm{dB} / \mathrm{s}$} & $0.87 \mathrm{~dB} / \mathrm{s}(0.48-1.27)$ & $\mathrm{P}<0.0001$ \\
\hline Good QoF & $0.25 \mathrm{~dB} / \mathrm{s}(-0.12$ to 0.61$)$ & $P=0.191$ & {$[-2.3$ to 2.8$] \mathrm{dB} / \mathrm{s}$} & $1.16 \mathrm{~dB} / \mathrm{s}(0.85-1.47)$ & $\mathrm{P}<0.0001$ \\
\hline
\end{tabular}

a strong correlation between modalities may likely be due to the dissimilar types and distribution nature of contrast agents, relatively poor MR time resolution, different field of view and scan planes and perhaps also the administration technique between modalities. In the optimal setting, absolute perfusion measurements of tissue blood flow, blood volume and mean transit time should be compared. However, this is complicated, even when using MR contrast agents which act as true intravascular agents, e. g., in cerebral perfusion [38].

The present study demonstrates the consequence of ROI selection in the quantification of perfusion in CD. Our data emphasize the importance of TIC QoF for reliability and reproducibility. Poor QoF [34], e. g., by fitting a burst-replenishment curve on a bolus injection examination [39], will obviously give unreliable results. We therefore recommend that curve fitting quality should be reported alongside test results in future publications. Also, using low perfused tissue as a reference will cause high uncertainty of the final results [40].

This study has some limitations. We did not apply Tofts (extended) model or any other model to reflect pharmacokinetic parame- ters, like absolute blood flow or permeability measures for pathological conditions [41], as our T1 measurements employing the variable flip angle technique gave unreliable results [42]. As an alternative, we used the absolute signal difference technique instead, which has recently been shown to have a linear relationship to contrast agent concentration at low contrast concentrations [43, 44].

Furthermore, CEUS was performed without deconvolution [45], thereby only providing semiquantitative measurements. Deconvolution is complex and relies on several assumptions $[45,46]$ that are difficult to fulfil and thus rarely used in daily practice nor in scientific work. A method called bolus tracking and burst replenishment is described by jirik et al. [47] but the repeatability is not yet established in humans.

Based on existing guidelines, bolus injection techniques were used for CEUS and DCE-MRE. A fixed dose and manual injection of SonoVue was chosen for CEUS quantification [48]. For DCE-MRE, gadolinium dose was bodyweight-dependent and administered with an automatic pump. We chose the bodyweight-dependent dose over the fixed dose based on the general recommendation for 

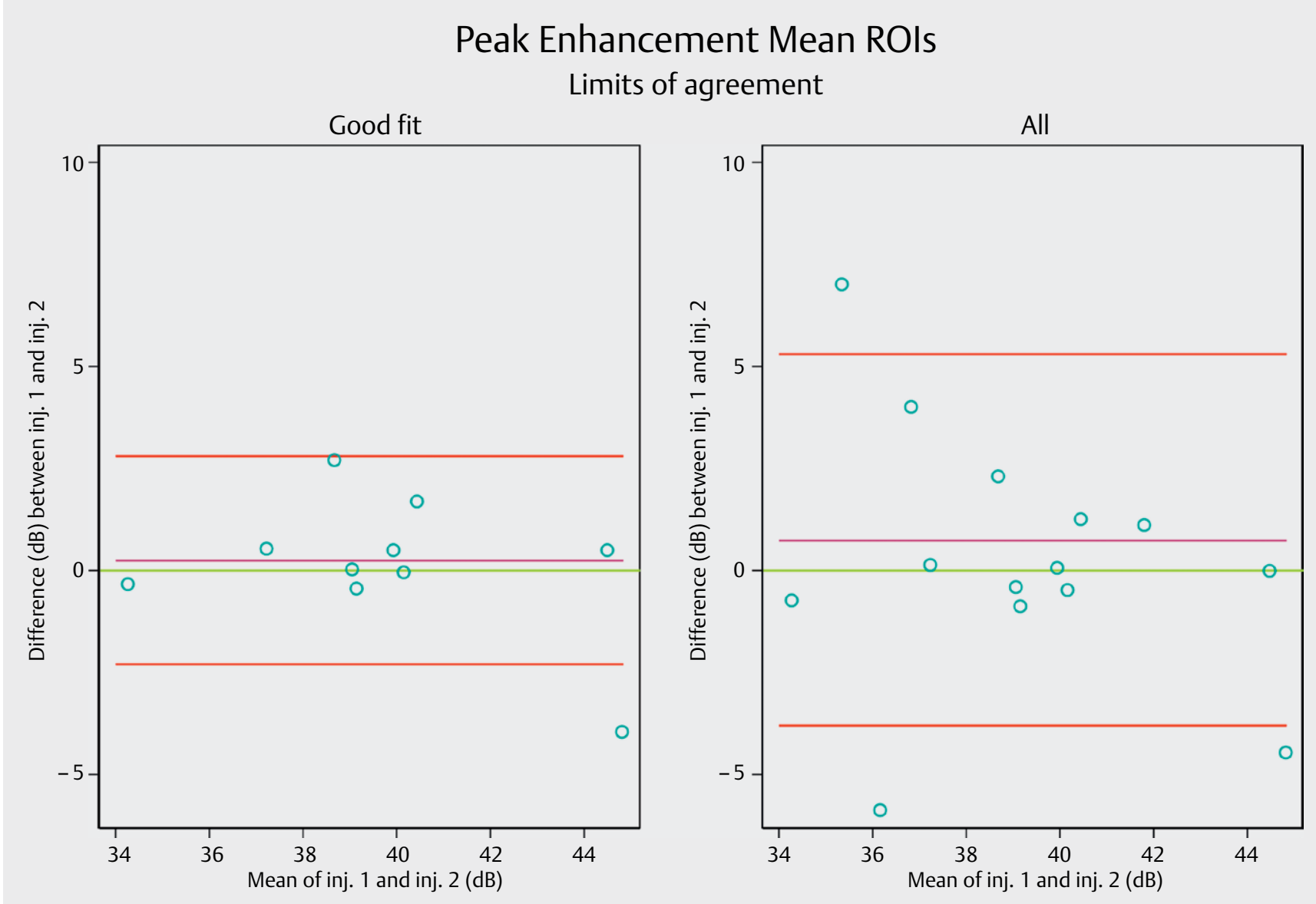

Fig. 6 Limits of agreement (LoA) for peak enhancement mean regions of interest. The purple line shows the observed average agreement. The red lines indicate $95 \%$ limits of agreement and the green line is the perfect average agreement. $R O I=$ region of interest. Inj. $=$ injection.

Table 5 CEUS region of interest quality of fit.

\begin{tabular}{|c|c|c|}
\hline Quality of fit & Injection 1 & Injection 2 \\
\hline Large ROI & $93.4(67-99)$ & $97.1(80-99)$ \\
\hline Good QoF & $97.4(82-99)$ & $97.4(90-99)$ \\
\hline Maximum peak ROI & $91.9(69-96)$ & $94.3(69-98)$ \\
\hline Good QoF & $92.6(86-96)$ & $94.2(86-96)$ \\
\hline Mean ROI & $93.7(82-98)$ & $93.1(75-97)$ \\
\hline Good QoF & $95.0(90-98)$ & $94.4(86-97)$ \\
\hline
\end{tabular}

Note - Numbers are percentages, parentheses are ranges in percentage

MR contrast administration [13]. We did not measure the exact length defined from an anatomical landmark, like the ileocecal valve, to ensure identical ROI location between modalities. Also, the CEUS scan planes were subjectively chosen and did not necessarily follow the standardized scan planes of MRI. The morphology of CD may vary even within short distances of the bowel and we cannot state that the exact same location was analyzed with the 2 methods $[44,49]$. However, we attempted to do so by analyzing the same bowel segment and the thickest part of it in each patient. As a result of the disease complexity, grading disease activity should ideally involve all changes in segmental inflammation in-
- Table 6 MR enterography reproducibility.

\begin{tabular}{l|c|c|}
$\begin{array}{l}\text { MR enterography global } \\
\text { Score (MEGS) }\end{array}$ & Kappa value & $\mathrm{P}$-value \\
\hline Total score & $\begin{array}{c}\mathrm{ICC}=0.79 \\
(0.59-0.90)\end{array}$ & $\mathrm{P}<0.0001$ \\
\hline $\begin{array}{l}\mathrm{K}=0.41 \pm 0.14 \\
\text { Bowel wall thickness }\end{array}$ & $\mathrm{P}=0.0016$ \\
\hline $\begin{array}{l}\text { Length of involvement } \\
\text { Lymph nodes }\end{array}$ & $\mathrm{K}=0.42 \pm 0.12$ & $\mathrm{P}=0.0004$ \\
\hline Enhancement pattern & $\mathrm{K}=0.51 \pm 0.19$ & $\mathrm{P}=0.0046$ \\
\hline Mural T2 signal & $\mathrm{K}=0.51 \pm 0.14$ & $\mathrm{P}=0.1816$ \\
\hline Perimural T2 signal & $\mathrm{K}=0.30 \pm 0.12$ & $\mathrm{P}=0.0056$ \\
\hline Comb sign & $\mathrm{K}=0.39 \pm 0.18$ & $\mathrm{P}=0.0148$ \\
\hline Fistulas & $\mathrm{K}=0.65 \pm 0.19$ & $\mathrm{P}=0.0003$ \\
\hline Note - Numbers in parenthesis are $95 \%$ confidence intervals \\
\hline Unless otherwise indicated, data are means \pm standard error \\
\hline ICC=intraclass correlation coefficient, $\mathrm{K}=\mathrm{kappa}$
\end{tabular}

stead of narrow sampling as used in this study. However, complex scores limit use in everyday practice [50].

Since there are no guidelines on the optimal scan plane, 2 different scan planes were employed for the assessment of the repeata- 
bility of CEUS ROIs. Full repeatability of findings from the same segment in an identical scan plane along with reproducibility between investigators is still warranted. However, based on the present findings within patient repeatability seems acceptable for the clinical use of CEUS in CD, especially when applying strict criteria for size and QoF. Lack of strict criteria or the use of a low perfused tissue as the reference tissue will lead to poor reproducibility $[35,40]$.

We chose to restrict the inclusion of patients to those with moderate to severe disease activity based on clinical symptoms. Investigating perfusion in a normal bowel wall is difficult because of peristalsis and a small ROI size results in poor QoF. However, clinical symptoms are often poorly correlated to objective signs of active disease. Based on wall thickness and biochemical findings, we covered the full disease spectrum of active small bowel disease.

In summary, there is only a moderate to weak correlation between CEUS and DCE-MRE slope-related and peak intensity parameters in CD. This is likely to be caused by the inherently different nature of the contrast agents and scanning modalities. Additionally, we have elucidated the importance of quality of fit for ROI selection in CEUS. The value of perfusion measurements as activity assessment in CD still remains to be clarified and validated against more objective endpoints.

\section{References}

[1] Peyrin-Biroulet L, Sandborn W, Sands BE, Reinisch W, Bemelman W, Bryant RV et al. Selecting therapeutic targets in inflammatory bowel disease (stride): determining therapeutic goals for treat-to-target. Am J Gastroenterol 2015; 110: 1324-1338 doi:10.1038/ajg.2015.233

[2] Wilkens R, Novak KL, Lebeuf-Taylor E, Wilson SR. Impact of intestinal ultrasound on classification and management of Crohn disease patients with inconclusive colonoscopy. Can J Gastroenterol Hepatol 2015; 29: 1-7

[3] Dubcenco E, Zou G, Stitt L, Baker JP, Jeejeebhoy KN, Kandel G et al. Effect of standardised scoring conventions on inter-rater reliability in the endoscopic evaluation of crohn's disease. J Crohns Colitis 2016; 22: S17 doi:10.1093/ecco-jcc/jjw120

[4] Panes J, Bouhnik Y, Reinisch W, Stoker J, Taylor SA, Baumgart DC et al. Imaging techniques for assessment of inflammatory bowel disease: Joint ECCO and ESGAR evidence-based consensus guidelines. J Crohns Colitis 2013; 7: 556-585 doi:10.1016/j.crohns.2013.02.020

[5] Taylor S, Mallett S, Bhatnagar G, Bloom S, Gupta A, Halligan S et al. METRIC (MREnterography or ulTRasound in Crohn's disease): a study protocol for a multicentre, non-randomised, single-arm, prospective comparison study of magnetic resonance enterography and small bowel ultrasound compared to a reference standard in those. BMC Gastroenterol 2014; 14: 142 doi:10.1186/1471-230X-14-142

[6] Horsthuis K, Bipat S, Bennink RJ, Stoker J. Inflammatory bowel disease diagnosed with us, $\mathrm{mr}$, scintigraphy, and ct: meta-analysis of prospective studies. Radiology 2008; 247: 64-79 doi:10.1148/ radiol.2471070611

[7] Murphy DJ, Smyth AE, McEvoy SH, Gibson DJ, Doherty GA, Malone DE. Subclassification of small bowel Crohn's disease using magnetic resonance enterography: A review using evidence-based medicine methodology. Clin Radiol 2015; 70: 1336-1343 doi:10.1016/j. crad.2015.07.008

[8] Zappa M, Stefanescu C, Cazals-Hatem D, Bretagnol F, Deschamps L, Attar $A$ et al. Which magnetic resonance imaging findings accurately evaluate inflammation in small bowel Crohn's disease? A retrospective comparison with surgical pathologic analysis. Inflamm Bowel Dis 2011; 17: 984-993 doi:10.1002/ibd.21414
[9] Steward M], Punwani S, Proctor I, Adjei-Gyamfi Y, Chatterjee F, Bloom $S$ et al. Non-perforating small bowel Crohn's disease assessed by MRI enterography: derivation and histopathological validation of an MR-based activity index. Eur J Radiol 2012; 81: 2080-2088 doi:10.1016/j.ejrad.2011.07.013

[10] Makanyanga JC, Pendsé D, Dikaios N, Bloom S, McCartney S, Helbren E et al. Evaluation of Crohn's disease activity: Initial validation of a magnetic resonance enterography global score (MEGS) against faecal calprotectin. Eur Radiol 2014; 24: 277-287 doi:10.1007/s00330-0133010-z

[11] Ziech MLW, Bossuyt PMM, Laghi A, Lauenstein TC, Taylor SA, Stoker ]. Grading luminal Crohn's disease: which MRI features are considered as important? Eur J Radiol 2012; 81: e467-e472 doi:10.1016/j. ejrad.2011.05.033

[12] Medellin-Kowalewski A, Wilkens R, Wilson A, Ruan J, Wilson SR. Quantitative contrast-enhanced ultrasound parameters in crohn disease: their role in disease activity determination with ultrasound. AJR Am J Roentgenol 2016; 206: 64-73 doi:10.2214/AJR.15.14506

[13] Rimola J, Rodriguez S, García-Bosch O, Ordás I, Ayala E, Aceituno M et al. Magnetic resonance for assessment of disease activity and severity in ileocolonic Crohn's disease. Gut 2009; 58: 1113-1120 doi:10.1136/gut.2008.167957

[14] Darwin F. On the primary vascular dilatation in acute inflammation. J Anat Physiol 1875; 10: 1-16

[15] Danese S, Sans M, de la Motte C, Graziani C, West G, Phillips MH et al. Angiogenesis as a novel component of inflammatory bowel disease pathogenesis. Gastroenterology 2006; 130: 2060-2073 doi:10.1053/j. gastro.2006.03.054

[16] Romanini L, Passamonti M, Navarria M, Lanzarotto F, Villanacci V, Grazioli L et al. Quantitative analysis of contrast-enhanced ultrasonography of the bowel wall can predict disease activity in inflammatory bowel disease. Eur J Radiol 2014; 83: 1317-1323 doi:10.1016/j. ejrad.2014.05.012

[17] Saevik F, Nylund K, Hausken T, Odegaard S, Gilja OH. Bowel perfusion measured with dynamic contrast-enhanced ultrasound predicts treatment outcome in patients with crohn's disease. Inflamm Bowel Dis 2014; 20: 2029-2037 doi:10.1097/MIB.0000000000000159

[18] Buckley DL. Uncertainty in the analysis of tracer kinetics using dynamic contrast-enhancedT1-weighted MRI. Magn Reson Med 2002; 47: 601-606 doi:10.1002/mrm. 10080

[19] Payen T, Coron A, Lamuraglia M, Le Guillou-Buffello D, Gaud E, Arditi M et al. Echo-power estimation from log-compressed video data in dynamic contrast-enhanced ultrasound imaging. Ultrasound Med Biol 2013; 39: 1826-1837 doi:10.1016/j.ultrasmedbio.2013.03.022

[20] Nylund K, Jirik R, Mezl M, Leh S, Hausken T, Pfeffer F et al. Quantitative contrast-enhanced ultrasound comparison between inflammatory and fibrotic lesions in patients with crohn's disease. Ultrasound Med Biol 2013; 39: 1197-1206 doi:10.1016/j.ultrasmedbio.2013.01.020

[21] Quaia E, Sozzi M, Angileri R, Gennari AG, Cova MA. time-intensity curves obtained after microbubble injection can be used to differentiate responders from nonresponders among patients with clinically active crohn disease after 6 weeks of pharmacologic treatment. Radiology 2016 0: 152461 doi:10.1148/radiol.2016152461

[22] Best WR, Becktel JM, Singleton JW, Kern F Jr. Development of a Crohn's disease activity index. National cooperative crohn's disease study. Gastroenterology 1976; 70: 439

[23] Harvey RF, Bradshaw JM. A simple index of Crohn's-disease activity. Lancet (London, England) 1980; 1: 514

[24] Silverberg MS, Satsangi ], Ahmad T, Arnott IDR, Bernstein CN, Brant SR et al. Toward an integrated clinical, molecular and serological classification of inflammatory bowel disease: report of a Working Party of the 2005 Montreal World Congress of Gastroenterology. Can J Gastroenterol 2005; 19 Suppl A: 5A-36A 
[25] Limberg B. Diagnosis of chronic inflammatory bowel disease by ultrasonography. Zeitschrift Für Gastroenterol 1999; 37: 495-508

[26] Zou KH, Tuncali K, Silverman SG. Correlation and simple linear regression. Radiology 2003; 227: 617-622 doi:10.1148/radiol.2273011499

[27] Raunig DL, McShane LM, Pennello G, Gatsonis C, Carson PL, Voyvodic JT et al. Quantitative imaging biomarkers: a review of statistical methods for technical performance assessment. Stat Methods Med Res 2015; 24: 27-67 doi:10.1177/0962280214537344

[28] Spinelli A, Correale C, Szabo H, Montorsi M. Intestinal fibrosis in Crohn's disease: medical treatment or surgery? Curr Drug Targets 2010; 11: 242-248

[29] Rimola J, Planell N, Rodríguez S, Delgado S, Ordás I, Ramírez-Morros A et al. Characterization of Inflammation and Fibrosis in Crohn's Disease Lesions by Magnetic Resonance Imaging. Am J Gastroenterol 2015; 110: 432-441 doi:10.1038/ajg.2014.424

[30] Röttgen R, Grandke T, Grieser C, Lehmkuhl L, Hamm B, Lüdemann L. Measurement of MRI enhancement kinetics for evaluation of inflammatory activity in Crohn's disease. Clin Imaging 2010; 34: 29-35 doi:10.1016/j.clinimag.2009.03.008

[31] Girlich C, Schacherer D, Jung EM, Schreyer A, Büttner R. Comparison between a clinical activity index (Harvey-Bradshaw-Index), laboratory inflammation markers and quantitative assessment of bowel wall vascularization by contrast-enhanced ultrasound in Crohn's disease. Eur J Radiol 2012; 81: 1105-1109 doi:10.1016/j.ejrad.2011.02.054

[32] Quaia E, Cabibbo B, De Paoli L, Toscano W, Poillucci G, Cova MA. The value of time-intensity curves obtained after microbubble contrast agent injection to discriminate responders from non-responders to anti-inflammatory medication among patients with Crohn's disease. Eur Radiol 2013; 23: 1650-1659 doi:10.1007/s00330-012-2754-1

[33] Moreno N, Ripollés T, Paredes JM, Ortiz I, Martínez M], López A et al. Usefulness of abdominal ultrasonography in the analysis of endoscopic activity in patients with Crohn's disease: changes following treatment with immunomodulators and/or anti-TNF antibodies. J Crohns Colitis 2014; 8: 1079-1087 doi:10.1016/j.crohns.2014.02.008

[34] Horjus Talabur Horje CS, Bruijnen R, Roovers L, Groenen MJM, Joosten FBM, Wahab PJ. Contrast enhanced abdominal ultrasound in the assessment of ileal inflammation in crohn's disease: a comparison with mr enterography. PLoS One 2015; 10: e0136105 doi:10.1371/journal. pone. 0136105

[35] Socaciu M, Ciobanu L, Diaconu B, Hagiu C, Seicean A, Badea R. Non-Invasive assessment of inflammation and treatment response in patients with crohn's disease and ulcerative colitis using contrast-enhanced ultrasonography quantification. J Gastrointestin Liver Dis 2015; 24: 457-465

[36] Taylor SA, Punwani S, Rodriguez-Justo M, Bainbridge A, Greenhalgh R, De Vita E et al. Mural crohn disease: correlation of dynamic contrast-enhanced $\mathrm{mr}$ imaging findings with angiogenesis and inflammation at histologic examination-pilot study. Radiology 2009; 251: 369-379 doi:10.1148/radiol.2512081292

[37] Makanyanga JC, Pendsé D, Dikaios N, Bloom S, McCartney S, Helbren E et al. Evaluation of Crohn's disease activity: initial validation of a magnetic resonance enterography global score (MEGS) against faecal calprotectin. Eur Radiol 2014; 24: 277-287 doi:10.1007/s00330-0133010-z

[38] Calamante F. Arterial input function in perfusion MRI: a comprehensive review. Prog Nucl Magn Reson Spectrosc 2013; 74: 1-32 doi:10.1016/j.pnmrs.2013.04.002
[39] Wong DD, Forbes GM, Zelesco M, Mason R, Pawlik J, Mendelson RM. Crohn's disease activity: quantitative contrast-enhanced ultrasound assessment. Abdom Imaging 2012; 37: 369-376 doi:10.1007| s00261-011-9792-Z

[40] Zink F, Kratzer W, Schmidt S, Oeztuerk S, Mason RA, Porzner M et al. Comparison of two high-end ultrasound systems for contrast-enhanced ultrasound quantification of mural microvascularity in crohn's disease. Ultraschall Med 2016; 37: 74-81 doi:10.1055/s-0034-1398746

[41] Tofts PS, Brix G, Buckley DL, Evelhoch JL, Henderson E, Knopp MV et al. Estimating kinetic parameters from dynamic contrast-enhanced t1-weighted MRI of a diffusable tracer: Standardized quantities and symbols. J Magn Reson Imaging 1999; 10: 223-232 doi:10.1002/ (SICI)1522-2586(199909) 10:3 <223::AID-JMRI2 > 3.0.CO;2-S

[42] Sourbron SP, Buckley DL. On the scope and interpretation of the Tofts models for DCE-MRI. Magn Reson Med 2011; 66: 735-745 doi:10.1002/mrm.22861

[43] Wang P, Xue Y, Zhao X, Yu J, Rosen M, Song HK. Effects of flip angle uncertainty and noise on the accuracy of DCE-MRI metrics: comparison between standard concentration-based and signal difference methods. Magn Reson Imaging 2015; 33: 166-173 doi:10.1016/j. mri.2014.10.005

[44] Sharman A, Zealley IA, Greenhalgh R, Bassett P, Taylor SA. MRI of small bowel Crohn's disease: determining the reproducibility of bowel wall gadolinium enhancement measurements. Eur Radiol 2009; 19 : 1960-1967 doi:10.1007/s00330-009-1371-0

[45] Mezl M, Jirik R, Harabis V, Kolar R, Standara M, Nylund K et al. Absolute ultrasound perfusion parameter quantification of a tissue-mimicking phantom using bolus tracking [Correspondence]. IEEE Trans Ultrason Ferroelectr Freq Control 2015; 62: 983-987 doi:10.1109/ TUFFC.2014.006896

[46] Gauthier M, Tabarout F, Leguerney I, Polrot M, Pitre S, Peronneau P et al. Assessment of quantitative perfusion parameters by dynamic contrast-enhanced sonography using a deconvolution method: an in vitro and in vivo study. J Ultrasound Med 2012; 31: 595-608

[47] Jirik R, Nylund K, Gilja OH, Mezl M, Harabis V, Kolar R et al. Ultrasound perfusion analysis combining bolus-tracking and burst-replenishment. IEEE Trans Ultrason Ferroelectr Freq Control 2013; 60: 310-319 doi:10.1109/TUFFC.2013.2567

[48] Piscaglia F, Nolsøe C, Dietrich CF, Cosgrove DO, Gilja OH, Bachmann Nielsen $\mathrm{M}$ et al. The EFSUMB guidelines and recommendations on the clinical practice of contrast enhanced ultrasound (ceus): update 2011 on non-hepatic applications. Ultraschall Med 2011 33-59 doi:10.1055/s-0031-1281676

[49] Borley NR, Mortensen NJ, Jewell DP, Warren BF. The relationship between inflammatory and serosal connective tissue changes in ileal Crohn's disease: evidence for a possible causative link. J Pathol 2000; 190: 196-202 doi:10.1002/(SICI)1096-9896(200002)190:2<196::AIDPATH513>3.0.CO;2-5

[50] Calabrese E, Zorzi F, Zuzzi S, Ooka S, Onali S, Petruzziello C et al. Development of a numerical index quantitating small bowel damage as detected by ultrasonography in Crohn's disease. J Crohns Colitis 2012; 6: 852-860 doi:10.1016/j.crohns.2012.01.015 